\title{
Why do some UK SME's still find the implementation of a New Product Development process problematical? An Exploratory Investigation.
}

Jonathan D Owens. Senior Lecturer in Operations Management, Lincoln Business

School, University of Lincoln. UK.

\begin{abstract}
The long-term survival of a business often hinges upon its ability to successfully introduce new products into the market place. These new products and their successful development can be the lifeblood of a company. Thus, NPD is a major consideration for most organisations. New products can provide the stimulus for the company to grow and produce profitable returns. Additionally, new products can gain new markets and market shares and subsequently help to defend against competitive pressures. Some businesses not only want to accelerate their NPD efforts, they also like to be a 'first to market' business. However, this strategy has its own risks as well as competitive advantages. There are numerous cases where businesses first to launch a new product did not profit from their innovations as much as their followers. Therefore, across numerous businesses NPD is one of the leading areas for focus, as companies seek to reduce time to market, access new technologies and develop more and better products. Subsequently, the consistent development and introduction of new products that customers' value can be an important criteria for business growth and prosperity. This research is exploratory in nature and provides empirical support to several propositions found in the innovation management literature on the development of new products. This paper examined why product development delays occur, the nature of these delays, and what could be done in order to avoid them.
\end{abstract}

\section{Keywords}

New Product Development, New Products, Product Innovation, Product Development Cycle Times.

\section{Introduction}

Intense global competition, rapid technology change and shifting patterns of world market opportunities compel companies to continually invest in New Product Development (NPD); if not for profit, then for survival, and this is considered to be the one of the key's to success for many businesses (Booz, Allen and Hamilton, 1991; Cooper and Edgett, 2003; Gerwin and Ferris, 2004; Hart et al, 2003; Wheelwright and Clark, 1992). Subsequently, the advance of new products and their development is widely recognised as an important source of competitive advantage (Owens, 2004). One issue that assists this, is timeliness and having the flexibility to readily expedite the NPD process (Owens and Davies, 2000). Great importance has been given to this issue due to the increasing costs of slow product development. The "time is money" 
scenario has mostly been closely associated with NPD, however, the realisation many businesses are facing up to is just how much this process is costing, in order for it remain competitive and profitable (Ozer, 2004). Hutlink et al (2000) indicates products that come to market six months late but on budget earn thirty three percent less profit over five years. In contrast, coming out on time and fifty percent over budget cuts profits by only five percent (Cooper et al, 2004a). Davis (2002) suggests businesses with short product development cycles often outperform businesses with long development cycles.

\section{Historical Background to NPD}

Some businesses not only want to accelerate their NPD efforts, they also like to be a 'first to market' business. However, Porter (1985) indicates this strategy has its own risks as well as competitive advantages. There are numerous cases where businesses first to launch a new product did not profit from their innovations as much as their followers, for example, Bowmar (pocket calculator) and Xerox (office computer). Robinson and Chiang (2002) suggest several strategies to accelerate product and process development and these can be summarised as:

- Reliance on external sources through buying, licensing or out sourcing.

- Reliance on intensified internal R\&D programmes through increasing rewards for successful performance, organising internal competition in research, and initiating simultaneous $R \& D$ on successive stages of innovation.

- Reliance on innovative R\&D management strategies such as peer reviews to accelerate progress, avoiding the quest for perfection, and closer integration of $\mathrm{R} \& \mathrm{D}$ with other functions.

Robinson and Chiang (2002) also indicate this is a positive step in understanding how companies can accelerate their innovation processes; however, it needs empirical testing in order to determine which strategies work best, under what conditions, and for which type of products.

Another approach is to study the deficiencies of existing product development systems. For example, Nonaka and Takeuchi (1995) suggest a successful NPD 
process is more like the game of rugby than a relay race. Rugby is a team effort where its members continually interact until the game is over. Whereas, a relay race is more like a typical sign-off procedure followed in many companies whereby the job moves from one functional department to another. Such linear, relay race-type processes are often slow, inflexible, and in efficient. Schilling and Hill (1998) found fast-cycle businesses prefer teams over functions and departments, they use time as a critical performance measure, and they insist everyone learn about customers, competitors, and the businesses own operations, not just top management.

Cooper and Kleinschmidt (2000) found although many managers profess to have a systematic process plan in place for product development, an audit of what actually happens 'on the shop floor' reveals many gaps and deficiencies. They found a number of often-critical activities were omitted altogether, and other key activities were superficially or weakly undertaken. Another study (Bajaj et al, 2004) relating to product success rate with the number of product design activities performed found approximately thirty four percent of the businesses involved in the study performed all the key design activities. The study found performing more product design activities, as compared with engaging in fewer activities, was consistently associated with statistically significantly higher new product success rates.

However, performing more steps can take more time. It appears that in order to rush products to market, many key NPD activities are often ignored. This can lead to poor design, product malfunctioning, product liability claims, expensive product recalls, and potential higher production costs (Cooper et al, 2004a). The challenge is not to cut corners or avoid undertaking important steps, but to carry out the task of NPD faster without sacrificing quality or eliminating steps.

\section{Research Methodology: the "holistic" approach}

This study is exploratory in nature and examined why product development delays occur, the nature of these delays, and what could be done in order to avoid them.

Due to the dynamic nature of the area of study where NPD decision-making is largely based on the intuitive competencies of the core NPD team/personnel, it was decided 
to use multiple research strategies. Based on the ontological foundations of constructivist realism, the findings should be understood as constructions rather than descriptions (Cupchik, 2001). From this perspective the researcher employed a multistage approach using both quantitative (survey) and qualitative research techniques (interviews). The implications are that the twelve SME's involved in this study can have different 'millstones' hanging from their epistemological necks. However, in this paper, the arbitrary boundaries and assumptions that separate them have been eliminated where the researcher is hopeful this interplay between descriptive richness and experimental precision can bring accounts of social phenomenon within the NPD arena to progressively greater levels of clarity (Cupchik, 2001). The philosophical underpinning is "we can uncover all kinds of relationships in our hard data, but it is only through the use of soft data we are able to explain them" (Mintzberg, 1979). Subsequently, the focus on this research is how the core NPD team personnel at the twelve SME's view their world and consider what they see as reality, according to their own paradigm (Radford and Goldstein, 2002), where the outcomes of the research will be relative to the researcher, the researched and the reader's interpretation (Creswell, 1994).

\section{Piloting of Data Collection Methods}

The pilot case study helped the researcher refine the data collection plans with respect to both the content of the data and the procedures to be followed (Gill and Johnson, 1997). The pilot inquiry was much broader and less focused than the ultimate data collection methods and covered both substantive and methodological (Yin, 1994) issues. Therefore, in an effort to develop a more reliable data collection method, a pilot test of both quantitative (survey) and qualitative research techniques (interviews) was conducted.

Management and staff of an SME were used to pilot the two research techniques. This SME was currently involved with a research programme at the researcher's institution and frequently practised the development of a new product therefore, this was both an accommodating and easily accessible company to pilot. As a direct result from this pilot study, feedback and experiences resulted in some of the questions being modified and changed. 


\section{The Survey}

The survey was the first method of data collection and distributed to all core NPD personnel who were involved with NPD at their respective company. A 'cooling off' (Wisker, 2001) period of one month was allowed for each respondent to complete their questionnaire. Once this period had passed the researcher assessed the quantity of returned questionnaires for each SME, before following up in an attempt to maximise the feedback.

There was some attention to the way questions were worded in the survey (Churchill, 1995). Questions were worded using direct and specific language, with a conversational tone (Frey and Mertens Oishi, 1995). Responses were mutually exclusive where only one tick was required. Wherever appropriate, “don’t know” and "N/A" response were offered in a consistent order. Some questions were written at the same time as scale development so that consequence of items and responses on the question could be included. The questions were arranged in a certain order aimed at being uncomplicated to make the questions 'user friendly'. All questions were grouped into manageable amounts, and consistency in questioning was also provided. The type of question varied to provide interest (Gill and Johnson, 1997), although towards the end of the questionnaire similarity in the questions was difficult to avoid.

\section{The Interview}

The interviewing process was conducted over a six-month period with the researcher being allowed open access to each SME in order to clarify any matters arising from the previous meetings. At the start of the interview the researcher explained the purpose of this study and requested the co-operation of the respondents to give their sincere answers to the questions, stressing that all answers were treated in the strictest confidence. Documents such as memorandums, newsletters, manuals and procedures relating to the research were collected, examined and analysed for relevant information. Special attention was given to documents and data relating to initiatives and activities that were carried out as response to commence on a NPD project. 


\section{Sample Selection}

The findings for this research are based upon field interviews and a survey of core team members involved in developing new products. A judgement or purposive sampling method was used in order to attempt to gain a cross-section of key/core participants in the NPD process of twelve similar manufacturing based small to medium enterprises (SME) in the North of England. A total of eighty five personnel were involved in the study that were perceived to be a key part in the NPD process at their respective company.

The specific businesses chosen for the study were selected because they were known to have active NPD programmes for a number of years and, they had experienced both important successes and failures in their innovation programmes. Each company was involved in similar NPD cycle times of approximately eighteen month to two years. Additionally, the researcher had previous experience working with these businesses; subsequently both access and cooperation were relatively unproblematic and unrestricted, thus facilitating the data collection method satisfactorily.

\section{Response Rate}

The total number of responses received was forty-nine which gave a response rate of just under fifty eight percent. One reason for this quite good response rate is the researcher's good working and professional relationship with each of the SME's. However, it must be noted the researcher had in no way influenced and/or biased the results. The reasons for the thirty-six non-returnees were varying from they did not want to participate in the study, to time constraints, had left their current employer, did not feel they were a core member of the NPD personnel/team etc. Therefore, there was no clear identifiable trend for this phenomenon. 


\section{Research Findings}

\section{Need to Accelerate the NPD Process}

When asked if the respective businesses had experienced a need to reduce development time for its new products, eighty-eight percent of the respondents answered "yes.” Additionally, eighty-seven indicated there had also been increased pressure to develop more new products. Numerous respondents suggested there was a fine balance between getting the product out early and getting it out too early. To rush the product to market, one needs to be particularly concerned with quality (Wong, 2002). Two major reasons given by the respondents for accelerating the NPD process were:

1. Increased domestic and global competitive pressures.

2. Rapid technological changes.

Other reasons included:

- Market demand - i.e. customers requiring new products developed quickly.

- A need to meet corporate growth objectives.

- Shortening of product life cycles (a combined effect of rapid technological changes, competitive activities and market requirement changes).

- Pressure from senior management to speed product development

- A desire to be first in an emerging new market

An overview of these and other reasons are illustrated in Figure 1, the results from the NPD process assessment. In addition to this there were a range of comments made by the respondents regarding the need to accelerate the NPD process:

- “...because competitors, primarily overseas, are taking our business away from us. The fast changing nature of our society is something we are still struggling to come to grips with. We are finding more and more often people don't want something that will last for five years, never mind 
twenty, they want change more often and we are finding we have to respond to that and quickly.”

- “...because product life cycles seem to be getting ever shorter, therefore the base or starting blocks erode faster than they use to. To keep a grip on sales, we need to bring new products to market faster.”

- "The fact that new materials and processes are being developed at an ever quicker pace demands that we must be alert and receptive to using them in news ways, as if we don't our competitors will.”

\begin{tabular}{|c|c|}
\hline $\begin{array}{l}\text { Reasons to Accelerate Product Development } \\
\text { - } \quad \text { Increased Competition (42\%) } \\
\text { - } \quad \text { Rapid Technological Changes (29\%) } \\
\text { - } \quad \text { Market Demands (11\%) } \\
\text { - } \quad \text { To meet growth objectives (11\%) } \\
\text { - } \quad \text { Shortening of Product Life Cycle (8\%) } \\
\text { - } \quad \text { Senior Management Pressures (8\%) } \\
\text { - } \quad \text { Emergence of New Markets (5\%) }\end{array}$ & $\begin{array}{l}\text { Reasons for Product Development Delays } \\
\text { - } \quad \text { Poor definition of product requirements } \\
\text { (71\%) } \\
\text { - } \quad \text { Technological Uncertainty (58\%) } \\
\text { - } \quad \text { Lack of Senior Management Support (42\%) } \\
\text { - } \quad \text { Lack of Resources (42\%) } \\
\text { - } \quad \text { Poor Project Management (29\%) } \\
\text { - } \quad \text { Other }(20 \%)\end{array}$ \\
\hline $\begin{array}{l}\text { Team Members' major Concerns During the } \\
\text { NPD Process } \\
\text { - } \quad \text { Management Style (53\%) } \\
\text { - } \quad \text { Lack of attention to details (47\%) } \\
\text { - } \quad \text { Limited support for innovation (32\%) } \\
\text { - } \quad \text { Lack of Strategic Thinking (18\%) } \\
\text { - } \quad \text { Poor Manufacturing Facilities (16\%) }\end{array}$ & $\begin{array}{l}\text { How Functional Groups delay the NPD Process } \\
\text { - Failure to give NPD programme priority } \\
\text { (58\%) } \\
\text { - Continually Changing requirements (58\%) } \\
\text { - } \quad \text { Poor internal communication (34\%) } \\
\text { - } \quad \text { Slow response (26\%) }\end{array}$ \\
\hline
\end{tabular}

Figure 1. NPD Process Assessment (Percentages are based on the responses of thirty eight respondents).

\section{Reasons for Product Development Delays}

Despite the increased pressure to develop more new products and the need to accelerate product development efforts, eighty seven percent of the respondents reported most of the reasons, which delayed product development in the past, still continue to exist in their businesses. As NPD process has been both well researched and documented since the late sixties, this finding is somewhat surprising in the twenty-first century. Based on the responses from filed interviews involving core 
members of the NPD team, several major reasons for development delays were identified in figure 1.

\section{Poor Definition of Product Requirements}

This was the issue most respondents cited as their reason for product development delays. Seventy-one percent of the respondents highlighted that the process was delayed due to poor understanding of customer requirements, and insufficient knowledge of a product's technology and market forces such as competition, suppliers, market forces, distributors etc. Subsequently, the lack of understanding necessitates frequent changes in the product development and marketing plans. Poor internal communication and relations also contributed significantly to the difficulty of defining product requirements and developing and freezing design specifications. Some of the respondents described this issue as:

- "We need to get a much better understanding of our customer's needs and desires. For us to get the customer feedback and interpret it for our own use seems to be a big grey area."

- "Changing product requirements causes more delays in product development than anything else. We don't have a crystal ball that can tell us exactly our future requirements; however, many times we inaccurately, or perhaps too hastily, set the requirements and live to regret them later."

- "We could reduce the definition problem by communicating the importance of identifying the customer's requirements early and accurately. For this we need to plan ahead better and work together with people in other departments across the company."

These quotes suggest that integrating $R \& D$, engineering, manufacturing, marketing, suppliers and the customer at an early stage in the NPD process is necessary for developing clear product requirements. Early involvement of various functional groups can help achieve commitment and clarify product requirements before too much time and money has been invented and opinions have been formed (Cooper, 2001; Wheelwright and Clark, 1992). Additionally, this can reduce the response time 
and need for frequent and unnecessary changes in product definition, marketing, design and production etc.

\section{Technological Uncertainties}

Fifty eight percent of the respondents claimed technological uncertainties as a major reason for delay. Once the delay occurs and newer technology becomes available, there may be a desire to incorporate the latest technological improvement into the product, subsequently; this can delay the product's development even more. The 'minor aesthetic improvements' or 'might as well syndrome' can also contribute to serious delays due to the inability to freeze product specification in a timely manner. Other common concerns associated with the uncertainty brought about by new technology included:

- "Is the new technology compatible with existing product components?"

- "How will the incorporation of new technology affect our ability to make incremental product innovations?"

- "Will the incorporation of new technology increase the marketability of the product?"

- "Can we ensure the quality and reliability of the new technology?"

- "How quickly can we develop or acquire the new technology?"

\section{Senior Management Support}

Forty-two percent of the respondents claimed the low priority given to NPD programmes, unrealistic expectations, short-term vision, lack of strategic thinking, risk averseness, and the inability; or perhaps inability; to learn from past failures were seen as major reason for product development delays. Most respondents indicated these issues were a reflection of senior management's attitudes toward innovation and NPD in general. Meyer et al (2005) claim such attitudes can affect an organisations cultural view about innovation. Representative comments regarding the role of senior management during NPD included: 
- "The lack of a common vision and its maintenance is our prime problem. In my opinion this is what senior management needs to do, but don't."

- When we've completed major product developments in a short period of time, quite often, senior management's active involvement and commitment has been the key to this success. That we should have the product ready by this date and there was no moving deadline. We had the top brass coaching and talking to boost up the staff morale, and the team seemed to thrive on its active involvement with the product development."

- "In our efforts to run more lean and profitable, we've stretched our personnel much further. This has created an even greater need for management to prioritise and specify what development efforts will benefit the company the most."

As the quotes suggest, senior management can play a major role in setting the climate for important innovative NPD programmes.

\section{Lack of Resources}

Forty two percent of the respondents indicated the lack of resources committed to NPD as an important reason for contributing towards programme delay. Part of this problem could also be attributed to lack of senior management's support for innovation. Some respondents claimed their management only gave innovation spurious "lip service". Other respondents complained too many inexperienced people were assigned to work on key projects. A few respondents noted resources were taken away from important projects that resulted in substantially slowing their progress.

\section{Poor Project Management}

Twenty nine percent of the respondents attributed development delays to poor project management practices, such as not monitoring the project's progress, lack of control systems, poor team and cross-functional meeting management practices, complex matrix management structures, undefined and conflicting roles. There were, however, some respondents who expressed resistance to project controls: 
- "The company uses both mini and major milestones. I resist them personally; I don't want my people pressured. I personally never use Gantt or Critical path Methods. I find them extremely unproductive. They are useful in moving equipment around, but quite useless in product development."

- "Product status reviews are helpful because they inform the people who need to know the current status."

It was evident that several businesses were experimenting with various project management tools and techniques. Some companies had wholeheartedly adopted project management without selling the concept to their NPD personnel. As a consequence, some NPD personnel were resisting and questioning the value of project management. Others noted, however, that the important NPD programmes would be virtually impossible to manage without project management.

Project management, like other managerial tools and techniques, needs to be implemented carefully so that its users see the tangible benefits that can come from its use.

\section{Other}

Twenty one per cent of the respondents indicated manufacturing limitations, delays in obtaining patents, set up problems, and problems with first tier suppliers as other reasons for product development delays. Some of the reasons are discussed and illustrated further:

- Removal of problems at the start or when first encountered. The research suggested these problems were not removed, because personnel involved in product development did not understand the problem correctly, they were not aware of the problem in time due to ineffective communications channels, they were given low priority to what later proved to be a key new product. Risk averse senior management allocating inadequate resources to key NPD programmes was another area that delays in product development was associated with. Some 
respondents suggested the difficulty in assessing the impact of delays on a product's commercial performance could also contributed to delays.

- Difficult to accomplish key NPD activities. NPD is a multi-stage, multidisciplinary process (Cooper et al, 2004b). It involves numerous development stages (Owens, 2000) such as: idea generation, idea screening, concept definition, defining product performance specs, finalising the product design, technical testing, market testing, assessing market potential, developing a business plan, developing prototypes, approval from senior management, launch, etc. It also involves the management of interfaces between $R \& D$, marketing, engineering and manufacturing (Cooper and Kleinschmidt, 2000). This research investigated how difficult to accomplish these and other NPD activities were perceived and how they might delay the NPD process. Subsequently, based on findings from both primary and secondary data a catalogue of commonly performed NPD activities was developed. The respondents rated each activity according to the degree of difficulty in carrying it out $(1=$ Not difficult, $3=$ Neutral/Undecided, $5=$ Very difficult). The ten most difficult to accomplish activities are illustrated in figure 2.

Research (Aiman-Smith et al, 2005; Davis, 2002; Hutlink et al, 2000; Ozer, 2004; Schilling and Hill, 1998) suggests for successful new products these activities need to be performed. However, in many NPD programmes several key activities that correlate highly with product success are either omitted or insufficiently undertaken (Cooper and Kleinschmidt, 2000). This research found the activities perceived as 'difficult' and 'very difficult' were also greatly associated with development delays. The results in figure 2 suggest the accomplishment of these tasks make innovation a major business challenge.

\section{Major Concerns during the NPD Process}

Meyer et al (2005) claim the management of technological innovation is complex, involving the effective integration of people, organisational processes and plans.” If there is a break down in any one of these elements or if they are not well integrated, the NPD process comes less effective (Sethi, 2000). In order to help assess the impact of these elements on new product participants the respondents were asked to describe some of the major concerns or problems encountered during NPD. Upon analysis of 


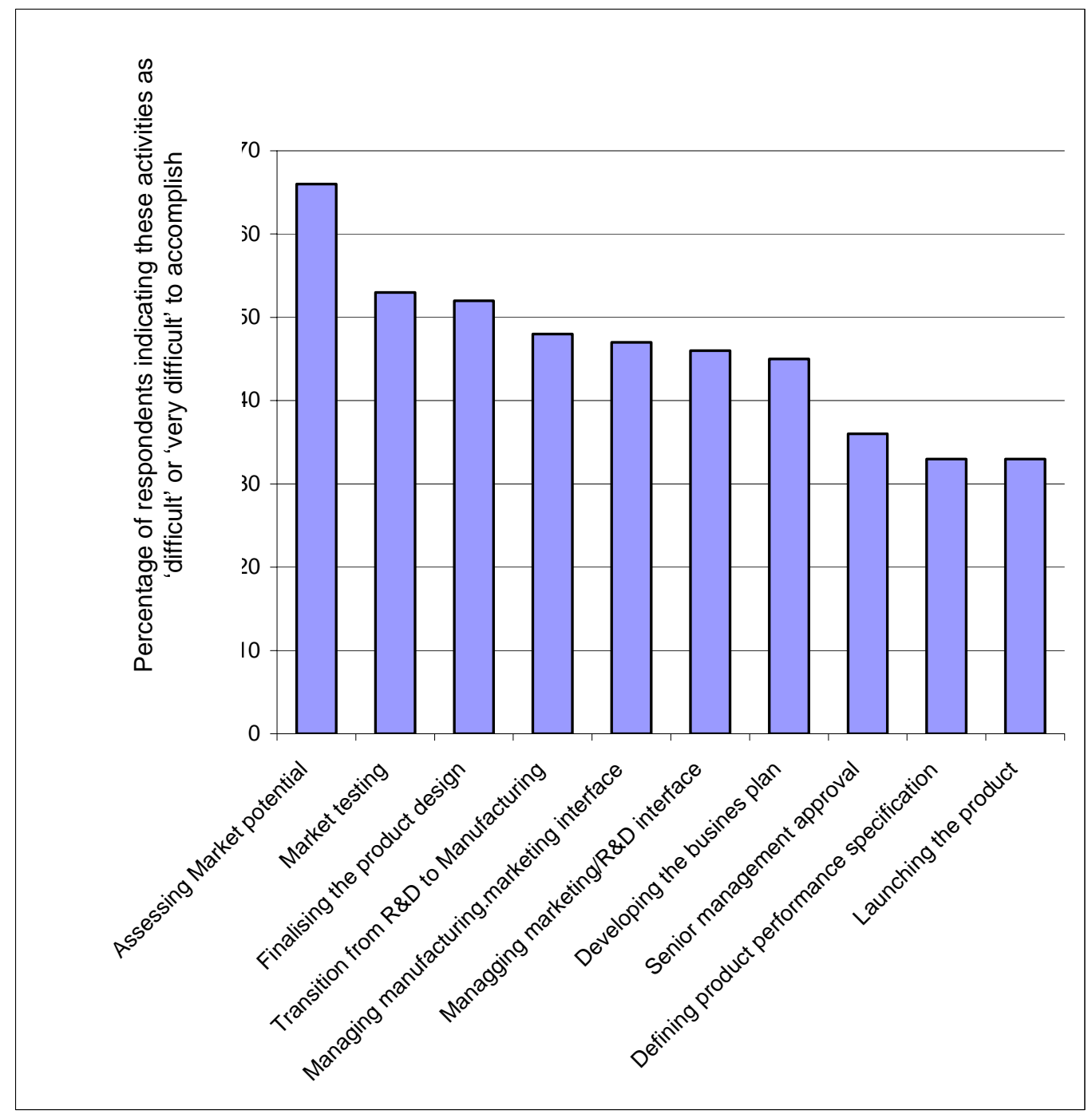

Figure 2. Most difficult to accomplish NPD activities.

the responses (figure 1) it suggested there were particular major concerns in the following:

- Management and organisational style

- Lack of attention to details

- Limited support for innovation

- Lack of strategic thinking

- Inadequate manufacturing facilities

Management and Organisational Style 
Fifty three percent of the respondents were concerned about their businesses' willingness to take appropriate action to facilitate innovation efforts. They experience excessive bureaucratic red tape, organisational inertia, risk-averseness and conservatism and, a lack of priority for NPD efforts. Also, some respondents indicated their businesses' often did not have the right mix of people to carry out effectively their NPD efforts. For example, some respondents claimed their businesses' needed more experienced personnel in NPD. While others suggested current products already in the market consumed a disproportionate amount of time. Some of the comments identifying these concerns were:

- "Our system is too structured and bureaucratic. There is not enough freedom and responsibility to let individuals get the job done."

- "They all talk about developing new products. When it comes to really doing, nobody seems to have the time for it. No one really wants to rock the boat."

- "We have a very real problem getting the right people involved in NPD. We use non-technical sales and marketing people when really technical people would be best. We need to staff with the appropriate people who have the right mix of skills to make our new product efforts successful."

- "Our company is not responsive enough to the requirements of our NPD efforts. We need a team approach with a strong project leader who has the responsibility and experience to deal with all the demanding issues we encounter. The teams should be relatively autonomous as to minimise interference for the managers."

\section{Lack of Attention to Details}

Forty-seven percent of the respondents were frustrated by the lack of attention paid to important details during the product development process. This is reflected in poor quality market research, frequent and unnecessary changes in product requirements, making decisions without forecasting their impacts and, inefficient use of resources. IBM speeds up NPD by using its resources wisely such as reusing proven parts and using effective quality control techniques to reduce production of defective parts (Meyer et al, 2005). Some of the comments made by the respondents were:

- "I get most frustrated by people who make up requirements they don't really understand and then change them later when they get the facts.” 
- "To think the required tolerance is plus or minus a very little when it really isn't, is very irritating. This slows down the process and increases cost unnecessarily."

- “We haven't taken the time to adequately define market and product requirements. As a consequence, we spend lots of time making guesses as to what will be required. Without clear definitions of these areas you waste considerable development time and resources.”

\section{Limited Support for Innovation}

Senior management often wants innovation for free; however, they never seem to commit the needed resources such as time, funds and people (Cooper et al, 2004a). One respondent (an engineer) claimed:

- "The resources most frequently requested are people, and it's the hardest resource to justify. It is not only hard to get approval for the personnel but it's a very competitive time in our industry. We can have positions unfilled for months, even years. We can shuffle jobs around, but there is so much red tape in order to make it happen, also something else will suffer further down the line as that person we have moved is not there to do their original job."

Thirty two percent of the respondents were frustrated by the lack of support and investment for innovation; the following is a summary of the key findings:

- “Pet” projects gather support while other important new products remained “orphans”.

- Not being able to work on new, potentially important projects

- $\quad$ Seeing key personnel being taken away from their projects and being reassigned to marginal projects.

This finding appears comparable with research by Cooper and Kleinschmidt (2000) on the importance of senior management's multi-dimensional role in fostering an innovative, highly interactive environment for NPD. 


\section{Lack of Strategic Thinking}

Eighteen percent of the respondents were irritated by senior management's perceived lack of strategic thinking. In doing so described their frustration as:

- "Management is busy fire fighting."

- "No one sees the big picture."

- "Lack of company focus."

- "Management has a pigeon hole mentality."

- Functional groups work in isolation.”

- "Management is not seeing that competition is emerging from several unrelated industries.”

- "Not realising that there are several alternative technologies available from other industries which could benefit the company.”

An R\&D manager expressed concern of this lack of strategic direction by:

- 'Senior management's time frame is too short. They only look thirty days down the road. They don't even want to tell you how much money you have for the year. They cannot grasp the level of risk, time frame and uncertainty required for NPD."

Lack of strategic thinking was a concern at functional level. Fifty eight percent expressed their concern at the low priority given to NPD efforts by functional groups. Functional departments were often seen as too busy solving the more immediate product line problems. As a consequence, NPD was ignored. Due to the low priority given to NPD, some functional groups may not be well prepared for meetings, do not pay attention to important details, are slow to respond, fail to promote good ideas through the business and, give excuses or blame others rather than accepting responsibilities. Some other ways in which functional groups can delay the NPD process are illustrated in figure 1.

Developing products quickly and successfully requires a team effort and an environment where team members can interact effectively (Sethi, 2000). Senior 
management can help this process by ensuring unnecessary restraints that block effective teamwork are removed.

\section{Poor Manufacturing Capabilities}

Sixteen percent of the respondents had concerns about their manufacturing facilities in their businesses. Their complaints were focussed around the availability of proper tooling, inadequate plant facilities, unrealistic and uncompetitive production times and costs and, outdated manufacturing facilities. To accelerate product development, IBM puts manufacturing high on its priority list, on par with technological leadership, customer service and, concern for employees (Meyer et al, 2005).

\section{Suggestions to Help Accelerate the NPD Process}

The respondents were asked how the NPD process could be accelerated in their respective businesses, their suggestions included:

\section{Active and Visible Senior Management Commitment}

A recurring theme that emerged in this study and others (Aiman-Smith et al, 2005; Cooper and Edgett, 2003; Suomala and Jokionen, 2003) was the role of senior management providing strategic vision, resources and, sustained commitment to product innovation. The respondents emphasised senior management needs to balance short term operating demands with long term innovation needs, avoid the 'not-invented-here' (NIH) syndrome, insist on better allocation of R\&D and resources, streamline decision-making, reduce the number of approvals needed and, be less risk averse. Many respondents indicated senior management was one of the greatest contributors to short development times. Management commitment in terms of financial and personal resources was the most important form of support. Some respondents' also emphasised senior management needs to be aware of product development problems and encourage innovation effectiveness programmes and innovation audits on a business wide basis. 


\section{Early Involvement of Functional Groups}

Forty percent of the respondents indicated that to accelerate NPD, key groups such as $R \& D$, marketing, engineering and, manufacturing should be involved very early in the process. It was also suggested interdepartmental communication can be promoted though joint rotation, regular joint review meetings, seminars, joint customer visits ( $R \& D$, engineering, manufacturing and marketing), social interactions and, through physical proximity of work places. For example, in its efforts to bring R\&D closer to marketing and manufacturing, IBM moves some of its researchers out of the development laboratories into the corresponding departments. This helps put the research background into other departments and prevents the R\&D personnel from being viewed as an isolated member of the business (Meyer et al, 2005). Suomala and Jokionen (2003) suggest early involvement of various functional groups also helps in defining product requirements before too much money has been spent and positions have been solidified.

\section{New Work Method}

Thirty three percent of the respondents suggested there was a need for their businesses to adopt a new method or style of working. These were characterised as:

- Encouraging greater use of modern technology for communicating and information processing.

- Using multiple approaches to solve problems, even explore unrelated areas for solutions.

- Being more creative and open to alternatives.

- Developing a sense of urgency and responding to problems quickly.

- Employing parallel processing of NPD tasks.

- Promoting flexible and more informal modes with greater priority given to informal communication versus formal e-memos and reports. 


\section{Early Market/Technical Testing}

Assuring the product is 'right' for the customers' needs is important in avoiding serious delays (Owens and Davies, 2000). Twenty-five percent of the respondents emphasised the need to test the product concept early and insisted on testing it on an "as-you-go" basis. One marketing manager claimed:

- “...we used to plan as though we knew what the project would be before we started and we were losing lots of money. Now we do a much better job of frontend work, not committing too much money but doing a smaller project and taking it out in the field to get real world evaluation and, we end up getting more of the right products."

Early involvement of various functional groups can also help achieve early testing because each group can make a special contribution to the process (Cooper et al, 1998). Active customer involvement facilitates the early testing and evaluation of the product (Hart et al, 2003).

\section{Effective New Product Organisations}

In order to accelerate the NPD process numerous respondents suggested their businesses needed to replace weak matrix approaches with strong product champions. Robinson and Chiang (2002) indicate matrix management was intended to be a compromise between functional and project structures but is often ineffective. They found matrices reflect the characteristics of the dominant form, either functional or project, but rarely both. Subsequently, its assurance as an effective organisational design for new products has seldom been realised. One of the respondents expressed disillusionment with the matrix system:

- “We've parted from the pure matrix approach to one where projects are often run in a single organisational group. This simplifies the overall co-ordination of people. Conceptually, matrix management works when you try to co-ordinate one 
project, but when you try to co-ordinate numerous projects at the same time it becomes a monumental task.”

Another suggestion given by the respondents was on building NPD teams. They suggested team membership should be determined largely by voluntary compliance and not by proclamation. A signing up process could be used to create a NPD team in which members have not been coerced to join, they have volunteered. Some of the respondents who were managers during product development claimed:

- "The best way to overcome many NPD obstacles is to have a strong champion. The champion should be allowed to pick his or her own team. People they can identify with, work with and, who will 'live' the project. We need less people involved in our teams, and we need to give them more autonomy and ownership."

- "We select a team that wants to win. Not too many people and just the ones we need. If we have a talented and committed team we can dramatically decrease the time required o get a new product through the system."

As can be seen for the previous five major recommendations a number of ideas have been suggested that could help accelerate the NPD process.

\section{Implications of this Research}

This study suggests that the NPD processes currently utilised need reassessing. This research indicates that not only does specific processes be examined but also a businesses culture be assessed to ascertain whether or not it is supportive to innovation, change and ultimately NPD. Research (Cooper et al, 2004b) indicates that to succeed in NPD and to develop fast-cycle capabilities, businesses need to adopt an integrated approach to NPD. Their approach is characterised by:

- Small, self-managing, multi functional project teams.

- Overlapping development phases, multi-learning, subtle control, organisational transfer of learning, built-in instability and, tracking time throughout the business. 
Additionally, research by Owens (2004) suggests a framework for New Product Development Learning (NPDL) and assessment to identify the initial sets of learning objectives (figure 3), which are required for NPD after the founding groundwork has been undertaken in the NPD organisation (figure 4). The objectives can be used in the analysis of learning needs, which should be undertaken before embarking on NPD and NPDL.

\begin{tabular}{|c|l|}
\hline Aim & \multicolumn{1}{c|}{ Work and Skills } \\
\hline Groundwork 1 & Developing the NPD Process \\
\hline Groundwork 2 & Implementing the NPD Strategy \\
\hline Groundwork 3 & Allocating Resources for NPD and NPDL \\
\hline
\end{tabular}

Figure 3. New Product Development Learning Objectives.

\begin{tabular}{|l|l|}
\hline Aim & \multicolumn{1}{|c|}{ Work and Skills } \\
\hline Objectives Set 1 & Organisational Analysis \\
\hline Objectives Set 2 & Barrier Demolition plus Interpersonal Skills \\
\hline Objectives Set 3 & Team Working \\
\hline Objectives Set 4 & Flexible Problem Solving \\
\hline Objectives Set 5 & Using Advanced Support Tools \\
\hline Objectives Set 6 & Facilitating Communication \\
\hline Objectives Set 7 & Maintaining Communication \\
\hline Objectives Set 8 & Decision Making \\
\hline Objectives Set 9 & Assessment of the NPD Process and NPDL \\
\hline Objectives Set 10 & NPD Risk Analysis \\
\hline
\end{tabular}

Figure 4. New Product Development Groundwork

Adoption of such practices could help minimise many of the major problems identified in this research. Findings from this research suggest the reason for product development delays and the actions, which can accelerate the process, are manageable. Thus, there is a strong need to change the NPD process, or indeed to learn the process more effectively in order to be more efficient, because eighty seven percent of the respondents reported most of the reasons that delayed NPD in the past continue to exist in their businesses.

This research has identified a number of areas deemed (by the respondents) as having significant impact on the NPD process performance in terms of its speed, cost, flexibility, quality, profitability, customer value etc. Most of these areas can be grouped into four major categories:

- Senior Management Support. 
- Early Integration of Functional Expertise in NPD.

- Availability of NPD Resources and their management.

- Organisational Environment that supports teamwork.

As can be seen there are similarities between these and those considered within the NPDL objectives illustrated in figure 3. 


\section{References}

Aiman-Smith, L; Goodrich, N; Roberts, D and Scinta, D (2005). "Assessing your organisation's potential for value innovation.” Research Technology Management, Mar/Apr, vol. 52, no. 2, pp 18-29.

Bajaj, A; Kekre, S and Srinivasan, K (2004). "Managing NPD: Cost and Schedule Performance in Design and Manufacturing.” Management Science, vol. 50, no. 4, pp527-538.

Bobrowski, P E (2000). "A framework for integrating external information into new product development: Lessons for the medical Technology Industry." Journal of Technology Transfer, vol. 2, no. 2, pp 181-192.

Booz, Allen and Hamilton (1991). New Product Management. Booz, Allen and Hamilton Inc., New York, USA.

Churchill, Jnr G A (1995). Marketing Research - Methodological foundations Sixth Edition. Dryden Press, Florida.

Cooper, R G (2001). Winning at New Products: Accelerating the process from idea to launch, $3^{\text {rd }}$ Edition. Perseus Books.

Cooper, R G and Edgett, S J (2003). "Overcoming the crunch in resources for new product development.” Research Technology Management, May/Jun, vol. 46, no. 3, pp 48-59.

Cooper, R G and Kleinschmidt, E J (2000). "New product performance: What distinguishes the star products?” Australian Journal of Management, vol. 25, no. 1, pp 17-46.

Cooper, R G; Edgett, S J and Kleinschmidt, E J (2004a). “Benchmarking Best NPD Practices - II.” Research Technology Management, May/Jun, vol. 47, no. 3, pp 5061.

Cooper, R G; Edgett, S J and Kleinschmidt, E J (2004b). “Benchmarking Best NPD Practices - III.” Research Technology Management, Nov/Dec, vol. 47, no. 6, pp 4357.

Cooper, R; Wooton, B and Bruce, M (1998). "Requirements Capture: Theory and Practice.” Technovation, vol. 18, no. 8/9, pp 497-511.

Creswell, J W (1994). Research design: Qualitative and Quantitative Approached, Sage Publications, London, UK.

Cupchik, G (2001). "Constructivist realism: an ontology that encompasses positivist and constructivist approaches to social sciences.” http://qualitative-research.net 
Davis, C R (2002). "Calculated Risk: A Framework for Evaluating Product Development.” MIT Sloan Management Review, summer, vol. 43, no. 4, pp 71-77.

Frey, J H and Oishi, S M (1995). How to Conduct Interviews by Telephone and in Person. Sage Publications.

Gerwin, D and Barrowman, N J (2002). "An evaluation of research on integrated product development.” Management Science, vol. 47, no. 7, pp 938-953.

Gerwin, D and Ferris, S J (2004). "Organising New Product Development Projects in Strategic Alliances.” Organisation Science, Jan/Feb, vol. 15, no. 1, pp 22-38.

Gill, J and Johnson, P (1997). Research Methods for Managers, Second Edition. Paul-Chapman publishing.

Hart, S J; Hutlink, E; Tzokas, N and Commandeur, H (2003). "Industrial Companies' Evaluation Criteria in new Product Development gates." Journal of Product Innovation Management, vol. 20, no. 1, pp 22-36.

Hutlink, E J; Hart S J; Robben, H S J and Griffin, A (2000). "Launch decisions and new product success: an empirical comparison of consumer and industrial products." Journal of Product Innovation Management, vol. 17, no.1, pp 5-23.

Meyer, M H; Anzani, M and Walsh, G (2005). “Innovation and Enterprise Growth: It took courage, focus and commitment at all levels for IBM to develop its nextgeneration product lines.” Research Technology Management, Jul/Aug, vol. 48, no. 4, pp 34-44.

Mintzberg, H (1979). “An emergent strategy of 'direct' research.” Administrative Science Quarterly, vol. 24, pp 580-589.

Nonaka, I and Takeuchi, H (1995). The Knowledge creating Company. Oxford University press, New York, USA.

Owens, J D (2004). “An evaluation of Organisational groundwork and learning objectives for New Product Development.” Journal of Enterprising Culture, Vol. 12, pp 303-325.

Owens, J D and Davies J (2000). "The Importance of a New Product Development (NPD) Process: Getting Started.” First European Conference on Knowledge Management, Bled School of Management, Bled, Slovenia, 26-27 October.

Ozer, M (2004). "Managing the selection process for new product ideas.” Research Technology Management, Jul/Aug, vol. 47, no. 4, pp 10 - 15.

Porter, M E (1985). Competitive Advantage. The Free Press, New York, USA

Radford, G P and Goldstein, S Z (2002). "The role of research methods in corporate communication.” Corporate Communications, vol. 7, no. 4, pp 252-256. 
Robinson, W T and Chiang, J (2002). "Product development strategies for established market pioneers, early followers, and late entrants.” Strategic Management Journal, vol. 23, no. 9, pp 855-864.

Rothaermel, F T and Deeds, D L (2004). "Exploration and exploitation alliances in Biotechnology: A system of new product development." Strategic Management Journal, vol. 25, no. 3, pp 201-219.

Schilling, M A and Hill, C W L (1998). "Managing the new product development process: strategic imperatives.” Academy of Management Executive, vol. 12, no. 3, pp. 67-81.

Sethi, R (2000). “New product Quality and Product Development Teams.” Journal of Marketing, vol. 64, no. 2, pp 1-14.

Suomala, P and Jokionen, I (2003). "The pattern of success in product development: a case study.” European Journal of Innovation Management, vol. 6, no. 4, pp 213227.

Wheelwright, S C and Clark, K B (1992). Revolutionising Product Development. Free Press, Macmillan Inc. New York, USA.

Wisker, G (2001). The Postgraduate Research handbook. Palgrave, New York, USA.

Wong, V (2002). “Antecedents of international new product rollout timeliness.” International Marketing Review, vol. 19, no. 2/3, pp 12-132.

Yin, R K (1994). Applications of Case Study Research. Sage Publications. 